\title{
Larvicultura de piabanha-do-pardo em aquários de cores diferentes
}

\author{
Deliane Cristina Costa(1), Marcelo Mattos Pedreira ${ }^{(1)}$, Marcos Vinicius Coraspe-Amaral(1), \\ Anselmo Eduardo Dupim ${ }^{(1)}$, Uidemar Barral(1) e Eglerson Duarte ${ }^{(1)}$
}

\begin{abstract}
(1)Universidade Federal dos Vales do Jequitinhonha e Mucuri, Departamento de Zootecnia, Laboratório de Aquicultura e Ecologia Aquática, Rua da Glória, no 187, Centro, CEP 39100-000 Diamantina, MG. E-mail: delianecristinac@yahoo.com.br, marcelo_ufvjm@hotmail.com, mvcoraspe@hotmail.com, anselmoganso@bol.com.br, uidek@hotmail.com, eglersonduarte@yahoo.com.br
\end{abstract}

\begin{abstract}
Resumo - O objetivo deste trabalho foi avaliar o efeito de diferentes cores de aquários na larvicultura da piabanha-do-pardo (Brycon sp.). Os tratamentos consistiram na utilização de aquários de cores claras (branca, verde e azul) e escuras (marrom e preta). Ao final do experimento, foram mensurados a sobrevivência, o peso, o comprimento total e a coloração das larvas, que foram comparados pelo teste de Tukey, a $5 \%$ de probabilidade. A sobrevivência foi menor (66,25\%), com maior taxa de canibalismo (17,08\%), no aquário de cor azul, quando comparado ao aquário de cor marrom $(84,17 \%)$, com baixa taxa de canibalismo $(6,25 \%)$. O comprimento total, o peso e a mortalidade não diferiram entre os tratamentos. A coloração das larvas escureceu progressivamente dos aquários mais claros para os mais escuros, o que interferiu no canibalismo e na sobrevivência. $\mathrm{O}$ aquário marrom promove maior valor de sobrevivência e menor taxa de canibalismo nas larvas de piabanha-do-pardo.
\end{abstract}

Termos para indexação: Brycon, canibalismo, coloração, mortalidade, pigmentação.

\section{Larviculture of piabanha-do-pardo in aquariums of different colors}

\begin{abstract}
The objective of this work was to evaluate the effect of different colors of aquariums on the larviculture of piabanha-do-pardo (Brycon sp.). The treatments consisted of the use of light- (white, green, and blue) and dark- (brown and black) colored aquariums. At the end of the experiment, survival, weight, total length, and color of the larvae were measured and compared by the Tukey test, at $5 \%$ probability. Survival was lower $(66.25 \%)$, with a higher rate of cannibalism $(17.08 \%)$, in the blue-colored aquarium when compared to the brown-colored one $(84.17 \%)$, with a low rate of cannibalism $(6.25 \%)$. Total length, weight, and mortality did not differ among treatments. The color of the larvae gradually darkened from the lighter to the darker aquariums, which interfered with cannibalism and survival. The brown aquarium promotes a greater survival value and a lower rate of cannibalism in larvae of piabanha-do-pardo.
\end{abstract}

Index terms: Brycon, cannibalism, coloring, mortality, pigmentation.

\section{Introdução}

A piabanha-do-pardo (Brycon sp.) é nativa da Bacia do Rio Pardo e tem despertado crescente interesse em razão dos resultados promissores na aquacultura, com boa resposta ao manejo reprodutivo (Andrade-Talmelli et al., 2002; Instituto Brasileiro do Meio Ambiente e Recursos Naturais Renováveis, 2004; Coraspe-Amaral et al., 2012). Estudos com cultivo de Brycon na piscicultura tiveram início com Von Ihering, na década de 1930, mas somente em 1994 surgiram grupos de pesquisa que intensificaram trabalhos deste gênero, para viabilizar o cultivo na piscicultura (Reynalte-Tataje et al., 2004; Pedreira et al., 2006, 2008).

$\mathrm{O}$ efeito das cores dos ambientes sobre a fisiologia e o comportamento dos animais vem se consolidando como área de amplo interesse para pesquisas (Volpato et al., 2004). A maioria dos estudos foca em mostrar os efeitos das cores do ambiente na sobrevivência e no canibalismo das larvas de peixes e organismos aquáticos (Tamazouzt et al., 2000; Yasharian et al., 2005), e a sua correlação com o estresse (Rotllant et al., 2003) e com o crescimento (Strand et al., 2007).

A cor do ambiente está relacionada à reprodução (Volpato et al., 2004), à visão e a aspectos adaptativos, como mudanças na pigmentação da pele dos peixes (Sugimoto et al., 2000). Muitos animais marinhos adéquam a cor da sua pele à do ambiente em que vivem, como a espécie Pagrus pagrus (pargo-vermelho) (Rotllant et al., 2003; Van Der Salm et al., 2004). Algumas características físicas do ambiente, como contraste da cor do tanque com o organismo, alimento e iluminação adequada têm importantes efeitos 
na percepção visual das larvas, o que aumenta o crescimento, a sobrevivência e a eficiência de captura (Ostrowski, 1989).

As espécies do gênero Brycon apresentam acentuado canibalismo na fase inicial de desenvolvimento (Romagosa et al., 2001; Andrade-Talmelli et al., 2002), que perdura por alguns dias. Fatores ambientais podem alterar o comportamento das larvas e afetar a conduta canibal (Fanta, 1995; Atencio-García \& Zaniboni-Filho, 2006). Para cada espécie de peixe, o canibalismo é influenciado pela interação de diversos fatores e estágios de desenvolvimento, o que demanda estudos específicos para cada situação de cultivo.

O objetivo deste trabalho foi avaliar o efeito de diferentes cores de aquários na larvicultura da piabanha-do-pardo.

\section{Material e Métodos}

O experimento foi conduzido na estação hidroelétrica da Companhia Energética de Minas Gerais (Cemig), no Distrito de Machado Mineiro, Município de Águas Vermelhas, MG, em janeiro de 2010, e teve duração de 15 dias. Foram utilizadas larvas de piabanha-do-pardo (Brycon sp.), de uma mesma desova, obtidas 24 horas

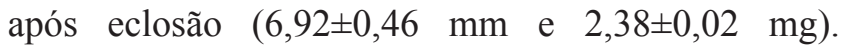
As larvas foram estocadas na densidade de 15 larvas por litro, em 20 aquários com $4 \mathrm{~L}$ de volume útil cada um, com aeração artificial constante, mantidos sob fotoperíodo natural de $12 \mathrm{~L}: 12 \mathrm{E}$ e intensidade luminosa de 780,8 440,08 Lux.

Os tratamentos consistiram na utilização de aquários de diferentes cores: três claras (branca, verde e azul) e duas escuras (marrom e preta), em delineamento inteiramente casualizado, com quatro repetições, o que totalizou 20 aquários.

As larvas foram alimentadas durante os primeiros cinco dias de vida com dez larvas de curimba (Prochilodus lineatus) por dia. A partir do sexto ao décimo quinto dia, as larvas foram alimentadas exclusivamente com ração comercial com $55 \%$ de proteína bruta, duas vezes ao dia, às $9 \mathrm{~h}$ e às $17 \mathrm{~h}$ até saciedade aparente.

Três vezes por semana, durante o período da manhã, foram medidos: temperatura e oxigênio dissolvido, com oxímetro YSI-55 (YSI Incorporated, Yellow Springs, $\mathrm{OH}, \mathrm{EUA})$; condutividade elétrica, com condutivímetro CD 4301 (Lutron BZ do Brasil, São
Paulo, SP); e pH da água, com peagâmetro Q 400 H (Quimis, Diadema, SP). Diariamente, os aquários foram sifonados para a retirada das sobras de alimento, com renovação de aproximadamente $40 \%$ do volume total da água. Em seguida, determinaram-se diariamente as taxas de mortalidade (a partir de animais mortos que não apresentaram sinais de ataque) e de canibalismo (a partir do somatório das larvas mortas predadas, com sinais de ataque, ou capturadas inteiras por outra larva).

Ao final do experimento, foi realizada a contagem final das larvas, e, em seguida, 15 larvas de cada repetição foram fixadas em formol $10 \%$ para posterior biometria (peso e comprimento total).

A coloração das larvas foi medida imediatamente após o término do experimento. Para as medições da luminosidade dos aquários e da cor das larvas, foi utilizado colorímetro CR-400 (Konica Minolta Business Solutions do Brasil Ltda., São Paulo, SP), que quantifica a cor em uma área delimitada pelo orifício da sonda do aparelho que mede $11 \mathrm{~mm}$. Em razão do tamanho reduzido das larvas, foi necessário agrupá-las de forma que a sonda fosse capaz de captar todo o espaço de leitura do aparelho, para que não ocorresse a leitura da área complementar adjacente ao redor do corpo destas.

As cores foram expressas em Lab, que é um sistema subtrativo de cor recomendado pela Commision Internationale L'Eclairage (Commission Internationale De L'Eclairage , 1976). Neste sistema, o L* representa a luminosidade da cor numa escala de $0-100$ pontos de preto para branco; a* é a posição entre vermelho $(+)$ e verde (-); e b* é a posição entre amarelo (+) e azul (-), sendo $\mathrm{a}^{*} \mathrm{e} \mathrm{b}^{*}$ as coordenadas de cromaticidade.

A intensidade da cor foi expressa pelo valor de saturação da cor, denominado croma $\left(\mathrm{C}^{*}{ }_{\mathrm{ab}}\right)$. Quanto menor a quantidade de branco ou preto existente, mais saturada é a cor (Pavlidis et al., 2006). Assim, uma cor está completamente saturada quando não contém nem branco nem preto. Estes valores foram calculados de acordo com as fórmulas: $\mathrm{H}_{\mathrm{ab}}=\arctan \left(\mathrm{b}^{*} / \mathrm{a}^{*}\right) ; \mathrm{C}^{*}{ }_{\mathrm{ab}}=$ $\left(a^{* 2}+b^{* 2}\right)^{0,5}$ e W $=100-\left[\left(100-L^{*}\right)^{2}+a^{* 2}+b^{* 2}\right]^{0,5}$, em que $\mathrm{H}_{\mathrm{ab}}$ corresponde ao tom da cor e à variação pela extremidade do círculo, cujo valor é expresso em graus; e $\mathrm{W}$ representa a brancura.

Para a comparação entre os tratamentos, os dados foram submetidos à análise de variância (Anova), e as médias foram comparadas pelo teste de Tukey, a 5\% de probabilidade, por meio do programa estatístico SAS, 
versão 8.0. Os resultados de sobrevivência, mortalidade e canibalismo, em percentual, foram avaliados quanto à normalidade e à homocedasticidade pelos testes de Lilliefors e de Cochran, respectivamente. Uma vez normais e homocedásticos, os dados foram analisados por Anova e as médias comparadas pelo teste de Tukey, a 5\% de probabilidade. Se os dados não apresentassem normalidade e homocedasticidade, mesmo após transformação arc sen, eram avaliados por teste não paramétrico de Kruskal-Wallis, a 5\% de probabilidade.

\section{Resultados e Discussão}

Os parâmetros de qualidade de água analisados foram semelhantes entre os diferentes tratamentos e não foram limitantes para a espécie avaliada. Os valores médios de temperatura, oxigênio dissolvido, $\mathrm{pH}$ e condutividade elétrica foram: $23 \pm 0,1^{\circ} \mathrm{C}, 7,6 \pm 0,1 \mathrm{mg}$ $\mathrm{L}^{-1}, 6,8 \pm 0,1$ e $42,6 \pm 0,8 \mu \mathrm{S} \mathrm{cm} \mathrm{cm}^{-1}$, respectivamente, e estão de acordo com os encontrados para larvicultura de Brycon (Reynalte-Tataje et al., 2004; Pedreira et al., 2008, 2012).

$\mathrm{O}$ valor $\mathrm{L} *$ representa a luminosidade de reflectância e de transmitância emitida pela parede dos aquários, que pode variar, de forma crescente, de 0 a 100 (do preto para o branco). Como observado no presente trabalho, o aquário branco apresentou maior luminosidade $(93,62 \pm 0,73)$, seguido do aquário verde $(66,49 \pm 0,29)$ e do azul $(53,61 \pm 0,48)$, e os aquários marrom e preto apresentaram os menores valores de luminosidade (43,21 $\pm 0,39$ e $25,43 \pm 1,46$, respectivamente).

A luminosidade do aquário de cor marrom pode ter influenciado positivamente o comportamento da piabanha-do-pardo, uma vez que resultou em maior sobrevivência e menor canibalismo, quando comparado ao de cor azul (Tabela 1). Nos demais tratamentos, a sobrevivência, a mortalidade e o canibalismo foram semelhantes entre si. O comprimento total e o peso não diferiram entre os tratamentos. Pedreira et al. (2008), no entanto, verificaram que aquários de cores escuras, como o marrom, promovem redução na sobrevivência das larvas de Brycon orthotaenia, quando comparados aos aquários de cor azul, e que o ambiente claro permitiu uma melhor visualização da presa, além de facilitar os manejos de limpeza.

$\mathrm{O}$ ambiente azul dos aquários aumentou os confrontos entre Leporinus macrocephalus, o que afetou a saúde dos animais e as taxas de sobrevivência (Andrade et al., 2006). Contudo, o cultivo em aquários de cor marrom e azul não interferiu na sobrevivência de Lophiosilurus alexandri e Prochilodus costatus (Pedreira et al., 2012).

No presente trabalho, considerou-se que a cor mais próxima à do ambiente natural da piabanha-do-pardo melhoraria seu "bem estar" e, consequentemente, a sobrevivência durante a fase larval. Os resultados obtidos confirmaram a superioridade do aquário marrom na sobrevivência de larvas e na menor taxa de canibalismo, quando comparado ao aquário azul, o que pode estar relacionado à adaptação das larvas à cor do Rio Pardo, que apresenta tons de coloração marrom.

As larvas de piabanha-do-pardo apresentaram canibalismo crítico a partir de 35 horas após a eclosão, que perdurou de forma intensa, porém mais amena, até o décimo segundo dia de vida (288 horas), a partir de quando este comportamento passou a ser menos frequente. A alta taxa de canibalismo observada no aquário de cor azul mostrou que, mesmo com muito alimento à disposição, a intensidade do canibalismo foi alta (Tabela 1).

O cultivo de tilápia-do-nilo (Oreochromis niloticus) e juvenil de linguado (Paralichthys dentatus) em aquários de cor azul deixou os peixes mais agressivos e favoreceu o aumento das interações agonísticas entre eles, característica que pode ser atribuída aos elevados

Tabela 1. Valores médios \pm desvio-padrão de sobrevivência, canibalismo, mortalidade, comprimento total e peso de larvas de piabanha-do-Pardo (Brycon sp.) ao final de 15 dias de experimento, em aquários com diferentes cores ${ }^{(1)}$.

\begin{tabular}{lccccc}
\hline Fundo de aquário & Sobrevivência (\%) & Mortalidade (\%) & Canibalismo (\%) & Comprimento total (mm) & Peso (mg) \\
\hline Branco & $77,08 \pm 5,83 \mathrm{ab}$ & $9,17 \pm 3,96 \mathrm{a}$ & $13,75 \pm 7,50 \mathrm{ab}$ & $19,43 \pm 1,05 \mathrm{a}$ & $63,95 \pm 5,29 \mathrm{a}$ \\
Verde & $75,18 \pm 3,60 \mathrm{ab}$ & $15,00 \pm 4,03 \mathrm{a}$ & $9,82 \pm 5,78 \mathrm{ab}$ & $19,41 \pm 0,55 \mathrm{a}$ & $65,19 \pm 8,30 \mathrm{a}$ \\
Azul & $66,25 \pm 6,43 \mathrm{~b}$ & $17,08 \pm 5,83 \mathrm{a}$ & $16,67 \pm 8,31 \mathrm{a}$ & $19,46 \pm 0,51 \mathrm{a}$ & $66,13 \pm 4,58 \mathrm{a}$ \\
Marrom & $84,17 \pm 9,21 \mathrm{a}$ & $9,58 \pm 1,66 \mathrm{a}$ & $6,25 \pm 3,69 \mathrm{~b}$ & $19,12 \pm 0,72 \mathrm{a}$ & $61,73 \pm 3,91 \mathrm{a}$ \\
Preto & $79,17 \pm 3,91 \mathrm{ab}$ & $10,41 \pm 3,15 \mathrm{a}$ & $10,42 \pm 4,58 \mathrm{ab}$ & $19,44 \pm 0,52 \mathrm{a}$ & $66,58 \pm 8,31 \mathrm{a}$ \\
\hline
\end{tabular}

${ }^{(1)}$ Médias seguidas de letras iguais, nas colunas, não diferem pelo teste de Tukey, a 5\% de probabilidade. 
níveis de cortisol plasmático encontrados em animais mantidos em ambiente de cor azul(Fanta, 1995; Merighe et al., 2004; Mclean et al., 2008). As larvas mantidas em aquário de fundo azul também apresentaram alta frequência de atividade locomotora, acompanhada por diversos momentos de confrontos agonísticos, o que aumentou a possibilidade de encontros entre larvas e provavelmente resultou em maior canibalismo.

As larvas mantidas em aquário de cor marrom apresentaram comportamento contrário. Elas localizavam-se próximo do substrato sobre o fundo do aquário, onde permaneciam à espera do alimento. Este comportamento contribuiu para a diminuição de encontro entre as larvas irmãs, o que reduziu a taxa de canibalismo.

Em relação ao comprimento e ao peso, as larvas de piabanha-do-pardo não foram afetadas pelas cores dos aquários. Larvas de curimatá-pioa ( $P$. costatus) apresentaram maior peso e comprimento final quando cultivadas em aquários de cor verde, em comparação às mantidas em aquários azul, marrom e preto (Pedreira et al., 2012). Cultivos de carpas (Cyprinus carpio) em aquários brancos favoreceram maior taxa de crescimento específico e melhor conversão alimentar do que o cultivo em fundo preto e verde (Papoutsoglou et al., 2000). Estes autores atribuíram o desempenho inferior nos aquários escuros às altas taxas de cortisol encontradas nos peixes cultivados nestes ambientes.

Algumas espécies de peixes, como os teleósteos, ajustam sua pele em resposta a mudanças na cor de fundo (Sugimoto et al., 2000), o pode ocorrer como resultado final de mecanismos de defesa (Bond, 1996). Este processo de mudança de cor, denominado de adaptação de fundo, é usado para estudar comunicações neuroendócrinas (Rotllant et al., 2003). Segundo Sugimoto (2000) e Van der Salm et al. (2006), estas mudanças de cor são decorrentes da agregação e da dispersão de pigmento, e das alterações na quantidade de pigmento e no número de cromatóforos.

Verificou-se mudança na pigmentação da pele das larvas de acordo com as cores dos aquários (Tabela 2). Os valores $a^{*}$ e $b^{*}$ representam, respectivamente, as proporções de vermelho e amarelo refletidas ou transmitidas pela pele das larvas. Foram observados maiores valores de a* para as larvas mantidas em aquários escuros e menores para os aquários de cores claras. Esses resultados estão de acordo com Imanpoor \& Abdollahi (2011), que obtiveram maiores valores de a* para juvenis de Rutilus Kutum em aquários vermelho e preto, e menores para as larvas dos aquários claros (branco, azul e amarelo). Doolan et al. (2007) também relataram maiores taxas de a* para a cor superficial de $P$. auratus cultivados em aquário preto, em comparação ao aquário branco. Os valores de $b^{*}$ foram superiores para as larvas dos aquários marrom e verde. Valores inferiores foram registrados para as larvas dos aquários preto e branco; porém, todos apresentaram valores positivos que tendem para a cor amarela (Imanpoor \& Abdollahi, 2011).

As larvas de piabanha-do-pardo mantidas em aquários marrom e preto apresentaram maior escurecimento da pele (menores valores de $\mathrm{L}^{*}$ ), e os maiores valores foram registrados para os aquários verde, branco e azul, respectivamente. Pavlidis et al. (2008) observaram elevados valores de $L^{*}$ para $P$. pagrus cultivados em aquários branco e azul, e menores para os aquários vermelho e preto, condição também relatada por Van der Salm et al. (2004). Doolan et al. (2007) constataram maiores valores de $\mathrm{L}^{*}$ para $P$. aurata cultivados em aquário branco, quando comparado aos cultivados em tanques pretos.

Tabela 2. Valores médios \pm desvio-padrão de $\mathrm{a}^{*}$ e $\mathrm{b}^{*}$ (cromaticidade), $\mathrm{L}^{*}$ (luminosidade), $\mathrm{C}^{*}{ }_{\mathrm{ab}}(\mathrm{croma}), \mathrm{H}_{\mathrm{ab}}^{\mathrm{o}}\left(\right.$ tom) $\mathrm{e}^{*}$ (brancura) da pele das larvas de piabanha-do-Pardo mantidas em aquários com diferentes cores, por 15 dias ${ }^{(1)}$.

\begin{tabular}{|c|c|c|c|c|c|}
\hline \multirow[t]{2}{*}{ Índices $\mathrm{CIE}^{(2)}$} & \multicolumn{5}{|c|}{ Fundo de aquário } \\
\hline & Branco & Verde & Azul & Marrom & Preto \\
\hline$\overline{a *}$ & $-0,56 \pm 0,25 c$ & $-0,02 \pm 0,01 b$ & $-0,67 \pm 0,01 c$ & $0,27 \pm 0,02 \mathrm{a}$ & $0,29 \pm 0,02 \mathrm{a}$ \\
\hline$b^{*}$ & $3,66 \pm 0,06 \mathrm{~d}$ & $5,22 \pm 0,01 b$ & $4,51 \pm 0,45 \mathrm{c}$ & $5,63 \pm 0,01 \mathrm{a}$ & $3,34 \pm 0,38 \mathrm{~d}$ \\
\hline $\mathrm{L}^{*}$ & $45,81 \pm 0,31 b$ & $48,37 \pm 0,02 \mathrm{a}$ & $42,01 \pm 0,01 \mathrm{c}$ & $41,34 \pm 0,01 d$ & $33,70 \pm 0,89 \mathrm{e}$ \\
\hline $\mathrm{C}^{*}{ }_{\mathrm{ab}}$ & $3,70 \pm 0,09 \mathrm{~d}$ & $5,21 \pm 0,01 \mathrm{~b}$ & $4,56 \pm 0,01 \mathrm{c}$ & $5,63 \pm 0,01 \mathrm{a}$ & $3,35 \pm 0,38 \mathrm{~d}$ \\
\hline $\mathrm{H}_{\mathrm{ab}}^{\mathrm{o}}$ & $-81,40 \pm 3,76 b$ & $-89,73 \pm 0,06 c$ & $-81,48 \pm 0,22 b$ & $87,30 \pm 0,26 \mathrm{a}$ & $85,01 \pm 0,59 a$ \\
\hline $\mathrm{W}^{*}$ & $45,68 \pm 0,30 \mathrm{~b}$ & $48,11 \pm 0,02 \mathrm{a}$ & $41,47 \pm 0,01 b c$ & $41,07 \pm 0,03 \mathrm{c}$ & $33,61 \pm 0,87 \mathrm{~d}$ \\
\hline
\end{tabular}

${ }^{(1)}$ Médias seguidas de letras iguais, nas colunas, não diferem pelo teste de Tukey, a 5\% de probabilidade. ${ }^{(2)}$ Índices do sistema subtrativo de cor proposto pela Commission Internationale L'Eclairage (1976). 
Para a piabanha-do-pardo, a saturação da cor $\left(\mathrm{C}^{*}{ }_{\mathrm{ab}}\right)$ foi maior em peixes cultivados em fundo marrom, verde e azul, e menor para as larvas mantidas em aquários preto e branco. Em Rutilus kutum, maiores valores de croma foram obtidos para as larvas mantidas em ambientes vermelho e amarelo, e menores para ambientes azul e branco (Imanpoor \& Abdollahi, 2011).

Foram observados maiores valores de tom $\left(\mathrm{H}^{\mathrm{o}}{ }_{\mathrm{ab}}\right)$ para as larvas dos aquários marrom e preto; menores para as larvas do aquário verde; e intermediários para as larvas dos aquários com fundo azul e branco. Os maiores valores observados nos aquários escuros estão próximos aos encontrados por Pavlidis et al. (2008), no cultivo de $P$. pagrus, em aquários com fundo preto. Fanouraki et al. (2007) não relataram diferenças para $\mathrm{H}_{\mathrm{ab}}^{\circ}$ em $P$. pagrus cultivados em ambiente com fundo preto, em comparação ao com fundo branco.

A pigmentação mais escura das larvas permite maior sobrevivência, uma vez que esta é fortemente relacionada à camuflagem (Stuart-Fox \& Moussalli, 2008). Em peixes reolíficos, a cor da água dos locais de desova serve de camuflagem para ovos e larvas, o que constitui uma estratégia de proteção da prole (Balshine $\&$ Sloman, 2011). De acordo com Van der Salm et al. (2006), a cor de fundo é o principal fator a influenciar a variação da pigmentação e, consequentemente, a coloração da pele do pargo-vermelho ( $P$. pagrus). A relação entre cor do peixe e cor do ambiente, bem como suas interações, também apresenta importância econômica. A cor de pele mais clara do pargo australiano (P. auratus) e do pargo-vermelho (P. pagrus), criados em tanques claros melhora a sua aceitação no mercado (Van Der Salm et al., 2004; Doolan et al., 2007).

Os resultados obtidos indicam que a coloração da pele teve implicações na sobrevivência e no canibalismo (Tabelas 1 e 2). O maior grau de pigmentação da pele observado nas larvas cultivadas em aquários escuros permitiu melhor camuflagem, o que provavelmente dificultou o canibalismo (pois diminui a percepção pela larva irmã) e aumentou a eficiência de captura das larvas de curimba. Estudos sobre o processo de pigmentação da pele dos peixes são complexos e apresentam grande importância tanto para o caráter biológico como para a regulação da reprodução (Volpato et al., 2004), o que favorece a sobrevivência e o desempenho dos animais (Pedreira et al., 2008, 2012).

\section{Conclusões}

1. O uso de aquário de cor marrom promove melhor sobrevivência e menor taxa de canibalismo nas larvas de piabanha-do-pardo.

2. O aquário de cor azul resulta em menor sobrevivência e maior canibalismo das larvas de piabanha-do-pardo.

3. O cultivo de piabanha-do-pardo em aquários escuros promove o aumento da pigmentação da pele das larvas, e o cultivo em aquários claros torna a pele das larvas mais clara.

\section{Agradecimentos}

À Fundação de Apoio e Desenvolvimento do Ensino Tecnológico da Escola Agrotécnica Federal de Salinas (Fadetec) e à Companhia Energética do Estado de Minas Gerais (Cemig), pelo fornecimento das larvas e do local para condução do experimento; e à Fundação de Amparo à Pesquisa do Estado de Minas Gerais (Fapemig), ao Conselho Nacional de Desenvolvimento Científico e Tecnológico ( $\mathrm{CNPq})$ e ao Banco do Nordeste do Brasil (BNB), pelo apoio financeiro.

\section{Referências}

ANDRADE, L.S. de; HAYASHI, C.; SOARES, C.M. Refúgios artificiais coloridos e o desempenho e sobrevivência de alevinos de Leporinus macrocephalus (Garavello \& Britsky, 1988). Ciência Rural, v.36, p.247-251, 2006. DOI: 10.1590/ S0103-84782006000100038.

ANDRADE-TALMELLI, E.T. de; KAVAMOTO, E.T.; NARAHARA, M.Y.; FENERICH-VERANI, N. Reprodução induzida da Piabanha, Brycon insignis (Steindachner, 1876), mantida em cativeiro. Revista Brasileira de Zootecnia, v.31, p.803-811, 2002. DOI: 10.1590/S1516-35982002000400001.

ATENCIO-GARCÍA, V.; ZANIBONI-FILHO, E. El canibalismo en la larvicultura de peces. Revista de Medicina Veterinaria y Zootecnia de Córdoba, v.11, p.9-19, 2006.

BALSHINE S.; SLOMAN, K.A. Parental care in fishes. Encyclopedia of Fish Physiology: From Genome to Environment, v.1, p.670-677, 2011.

BOND, C.E. Biology of fishes. Philadelphia: Saunders College Publishing, 1996. 750p.

COMMISSION INTERNATIONALE DE L'ECLAIRAGE. International de la iluminación y el color - CIE. Disponible en: $<$ http://www.cie.co.at>. Accedido el: 04 abr. 2011.

CORASPE-AMARAL, M.V.; PEDREIRA, M.M.; COSTA, D.C.; DUPIM, A.E.; PELLI, A.; OLIVEIRA, N.M. Time of feed transition and inclusion levels of exogenous protease in rations 
for piabanha-do-pardo Brycon sp. Hatchery. Acta Scientiarum. Animal Sciences, v.34, p.347-353, 2012. DOI: 10.4025/ actascianimsci.v34i4.14471.

DOOLAN, B.J.; BOOTH, M.A.; JONES, P.L.; ALLAN, G.L. Effect of cage colour and light environment on the skin colour of Australian snapper Pagrus auratus (Bloch \& Schneider, 1801). Aquaculture Research, v.38, p.1395-1403, 2007. DOI: 10.1111/j. 1365-2109.2007.01818.x.

FANOURAKI, E.; LAITINEM, J.T.; DIVANACH, P.; PAVILIDIS, M. Endocrine regulation of skin blanching in red porgy, Pagrus pagrus. Annales Zoologici Fennici, v.44, p.241-248, 2007.

FANTA, E. Influence of background colour on the behaviour of the fish Oreochromis niloticus (Cichilidae). Brazilian Archives of Biology and Technology, v.38, p.1237-1251, 1995.

IMANPOOR, M.R.; ABDOLLAHI, M. Effects of tank color on growth, stress response and skin color of juvenile Caspian Kutum Rtilus frisii Kutum. Global Veterinaria, v.6, p.118-125, 2011.

INSTITUTO BRASILEIRO DO MEIO AMBIENTE E DOS RECURSOS NATURAIS RENOVÁVEIS. Lista nacional das espécies de invertebrados aquáticos e peixes ameaçados de extinção com categorias da IUCN. 2004. Disponível em: <http:// www.ibama.gov.br>. Acesso em: 04 abr. 2011.

MCLEAN, E.; COTTER, P.; THAIN, C.; KING, N. Tank color impacts performance of cultured fish. Ribarstvo, v.66, p.43-54, 2008.

MERIGHE, G.K.F.; PEREIRA-DA-SILVA, E.M.; NEGRÃO, J.A.; RIBEIRO, S. Efeito da cor do ambiente sobre o estresse social em Tilápias do Nilo (Oreochromis niloticus). Revista Brasileira de Zootecnia, v.33, p.828-837, 2004. DOI: 10.1590/ S1516-35982004000400002.

OSTROWSKI, A.C. Effect of rearing tank background color on early survival of dolphin larvae. Progressive Fish-Culturist, v.51, p.161-163, 1989. DOI: 10.1577/1548-8640(1989)051<0161:EOR $\mathrm{TBC}>2.3 . \mathrm{CO} ; 2$.

PAPOUTSOGLOU, S.E.; MYLONAKIS, G.; MILIOU, H.; KARAKATSOULI, N.P.; CHADIO, S. Effects of background color on growth performances and physiological responses of scaled carp (Cyprinus carpio L.) reared in a closed circulated system. Aquacultural Engineering, v.22, p.309-318, 2000. DOI: 10.1016/S0144-8609(00)00056-X.

PAVLIDIS, M.; KARKANA, M.; FANOURAKI, E.; PAPANDROULAKIS, N. Environmental control of skin colour in the red porgy, Pagrus pagrus. Aquaculture Research, v.39, p.837-849, 2008. DOI: 10.1111/j.1365-2109.2008.01937.x.

PAVLIDIS, M.; PAPANDROULAKIS, N.; DIVANACH, P. A method for the comparison of chromaticity parameters in fish skin: preliminary results for coloration pattern of red skin Sparidae. Aquaculture, v.258, p.211-219, 2006. DOI: 10.1016/j. aquaculture.2006.05.028.

PEDREIRA, M.M.; LUZ, R.K.; MATIOLLI, C.C.; SANTOS, J.C.E. dos; SILVA, C.L. Larvicultura de matrinxã em tanques de diferentes cores. Pesquisa Agropecuária Brasileira, v.43, p.1365-1369, 2008. DOI: 10.1590/ S0100-204X2008001000015.
PEDREIRA, M.M.; SAMPAIO, E.V.; SANTOS, J.C.E.; PIRES, A.V. Larviculture of two neotropical species with different distributions in the water column in light- and dark-colored tanks. Neotropical Ichthyology, v.10, p.339-444, 2012. DOI: 10.1590/ S1679-62252012005000011.

PEDREIRA, M.M.; SIPAÚBA-TAVARES, L.H.; SILVA, R.C. Influência do formato do aquário na sobrevivência e no desenvolvimento de larvas de matrinxã Brycon cephalus (Osteichthyes, Characidae). Revista Brasileira de Zootecnia, v.35, p.329-333, 2006. DOI: 10.1590/ S1516-35982006000200001.

REYNALTE-TATAJE, D.; ZANIBONI-FILHO, E.; ESQUIVEL, J.R. Embryonic and larvae development of piracanjuba, Brycon orbignyanus Valenciennes, 1849 (Pisces, Characidae). Acta Scientiarum. Biological Sciences, v.26, p.67-71, 2004.

ROMAGOSA, E.; NARAHARA, M.Y.; FENERICH-VERANI, N. Stages of embryonic development of the "matrinxã", Brycon cephalus (Pisces, Characidae). Boletim do Instituto de Pesca, v.27, p.27-32, 2001.

ROTLLANT, J.; TORT, L.; MONTERO, D.; PAVLIDIS, M.; MARTINEZ, M.; WENDELAAR BONGA, S.E.; BALM, P.H.M. Background colour influence on the stress response in cultured red porgy Pagrus pagrus. Aquaculture, v.223, p.129-139, 2003. DOI: 10.1016/S0044-8486(03)00157-1.

STRAND, A.; ALANÄRÄ, A.; STAFFAN, F.; MAGNHAGEN, C. Effects of tank colour and light intensity on feed intake, growth rate and energy expenditure of juvenile Eurasian perch, Perca fluviatilis L. Aquaculture, v.272, p.312-318, 2007. DOI: 10.1016/j. aquaculture.2007.08.052.

STUART-FOX, D.; MOUSSALLI, A. Camouflage, communication and thermoregulation: lessons from colour changing organisms. Philosophical Transactions Royal Biological Science, v.364, p.463-470, 2008. DOI: 10.1098/rstb.2008.0254.

SUGIMOTO, M.; UCHIDA, N.; HATAYAMA, M. Apoptosis in skin pigment cells of the medaka, Oryzias latipes (Teleostei), during long-term chromatic adaptation: the role of sympathetic innervations. Cell and Tissue Research, v.301, p.205-216, 2000. DOI: $10.1007 / \mathrm{s} 004410000226$.

TAMAZOUZT, L.; CHATAIN, B.; FONTAINE, P. Tank wall colour and light level affect growth and survival of Eurasian perch larvae (Perca fluviatilis L.). Aquaculture, v.182, p.85-90, 2000. DOI: 10.1016/S0044-8486(99)00244-6.

VAN DER SALM, A.L.; MARTÍNEZ, M.; FLIK, G.; WENDELAAR BONGA, S.E. Effects of husbandry conditions on the skin colour and stress response of red porgy, Pagrus pagrus. Aquaculture, v.241, p.371-386, 2004. DOI: 10.1016/j. aquaculture.2004.08.038.

VAN DER SALM, A.L.; PAVLIDIS, M.; FLIK, G. The acute stress response of red porgy, Pagrus pagrus, kept on a red or white background. General and Comparative Endocrinology, v.145, p.247-253, 2006. DOI: 10.1016/j.ygcen.2005.09.010.

VOLPATO, G.L.; DUARTE, C.R.A.; LUCHIARI A.C. Environmental colour affects Nile tilapia reproduction. Brazilian Journal of Medical and Biological Research, v.37, p.479-483, 2004. DOI: 10.1590/S0100-879X2004000400004. 
YASHARIAN, D; COYLE, S.D.; TIDWELL, J.H.; STILWELL, W.E. The effect of tank colouration on survival, metamorphosis rate, growth and time to metamorphosis freshwater prawn (Macrobrachium rosenbergii) rearing. Aquaculture Research, v.36, p.278-283, 2005. DOI: 10.1111/j.1365-2109.2005.01242.x.

Recebido em 15 de agosto de 2011 e aprovado em 27 de fevereiro de 2013 